\title{
LA OFERTA DE HISTORIA ECONOMICA EN ESPAÑA
}

\author{
PEDRO FRAILE BALBIN \\ Universidad Complutense de Madrid
}

Los nuevos vientos liberales de la era postkeynesiana soplan amenazadores sobre la Historia Económica. En el mercado más competitivo y dinámico de nuestra industria, el mundo académico norteamericano, las nuevas fuerzas de la demanda han cambiado a la baja no solamente el precio de nuestro producto -el precio (relativo a otras materias) que los alumnos universitarios están dispuestos a pagar por las clases-, sino la cantidad de producto realmente vendida, es decir, el número de horas de Historia Económica impartida. El desinterés por nuestra materia es compartido por las lenguas, la filosofía, la historia, la literatura y el arte, y su seriedad ha desencadenado un proceso de reflexión nacional materializado en varios libros e informes técnico-pedagógicos sobre las ciencias sociales en el mundo académico americano*. El hecho fundamental al que estos estudios apuntan es que durante los últimos veinte años las matrículas en asignaturas de humanidades han decrecido en un 50 por 100 por causa de un cambio radical de valores. Mientras que hace diez años tan sólo el 40 por 100 de los alumnos encuestados elegían el objetivo "progreso financiero" como el fundamental de sus vidas, hoy lo hacen el 70 por 100 , y al mismo tiempo los objetivos tales como «alcanzar una filosofía vital significativa» han sufrido las bajas más acusadas de las encuestas.

Aunque los datos no son tan abundantes en nuestro país y, por lo tanto, las opiniones y prognosis han de producirse con más cautela, es fácil ver que un cambio parecido está ya en marcha en nuestro mundo académico. Nuestros alumnos son cada vez más pragmáticos, menos preocupados por las disciplinas económicas especulativas y más interesados por las aplicables y vendibles en un futuro mercado laboral incierto. A pesar de que la demanda

* Véanse, entre otros muchos, los informes de la Carnegie Foundation for the Advancement of Teaching (noviembre 1986) o el de la National Endowment for the Humanities, titulado "To Reclaim a Legacy» (1984), y los recientes besi-sellers del profesor de Filosofía de Chicago Allan Bloom, The Closing of the American Mind (How Higher Edu. cation Has Failed Democracy and Impoverished the Souls of Today's Students), Simon and Schuster, 1987, y del lingüista E. D. Hirsch, Cultural Literacy, Houton Mifflin, 1987. 
de Ciencias Económicas en general sigue mostrando una fuerte tendencia al alza, la situación de las asignaturas del programa más cercanas a las humanidades podría verse en geligro en_el_caso de_uno_liberalizarión del. mercadn académico. Si los presagios se confirman, no es difícil predecir que la curva de demanda de nuestro producto podría desplazarse pronto hacia la izquierda amenazando los precios (nuestros ingresos) y la cantidad de Historia Económica vendida (clases, libros publicados y conferencias).

¿Qué hacer ante esta amenaza? El resto de este comentario sugiere un plan en tres etapas para defender nuestros intereses profesionales en la eventualidad de una contracción drástica de la demanda de Historia Económica. En primer lugar, hemos de analizar las raíces del problema en el mercado donde se presenta con más agudeza, es decir, el mundo académico americano, para poder identificar sus causas con la mayor claridad; a continuación tenemos que estudiar no sólo la posible evolución futura de la demanda, sino la capacidad de nuestra oferta para competir en un mercado dinámico; $y$, finalmente, haremos cinco recomendaciones concretas para evitar la crisis o minimizar sus efectos.

Independientemente de la posible crisis intelectual y de valores que afecta a todas las sociedades occidentales, la causa más inmediata de la caída en la matrícula de Historia Económica es la creciente desregulación del mundo académico y el énfasis cada vez mayor en las fuerzas del mercado para resolver los problemas universitarios. El alumno goza de un poder de decisión cada vez más amplio para elegir asignaturas de acuerdo a su percepción de la utilidad potencial que de ellas pueda derivar, y al mismo tiempo el sistema académico se mueve cada vez más hacia un sistema de evaluaciones rigurosas por parte del alumno de las actividades, aptitudes, entusiasmo y efectividad del profesor. Esta peligrosa posibilidad de elección, y la existencia de cursos alternativos de mayor utilidad potencial, confieren una gran elasticidad a la demanda. Además, una oferta inflada por las bajas barreras de entrada de los años sesenta y setenta, y sin el armazón legal que reduzca la competencia y posibilite la fijación de precios dignos, contribuye a poner al mercado a merced de los consumidores (estudiantes). Estas, y no otras, son las razones de que a nivel no graduado haya una crisis de alumnos en casi todos los colleges y universidades y de que en programas graduados tan prestigiosos como el de Chicago se pueda obtener un $\mathrm{Ph}$. D. sin haber tomado ni un solo curso en la materia.

El segundo paso en nuestra defensa consiste en analizar la vulnerabilidad de nuestra oferta. ¿Qué posibilidades de competir tendríamos en un mercado libre y desregulado? La respuesta, naturalmente, vendrá dada por el nivel de los costes de producción. Para evaluar nuestra competitividad se comparan aquí los costes de producción de la Historia Económica en nuestro 
país y en los Estados Unidos, por ser este último el mercado que quizá se acerque más al modelo de competencia perfecta. Por tratarse de una actividad intensiva en mano de obra, la comparación se centra en los costes imputables al factor humano - el coste unitario del trabajo (cut) - y se suponen iguales los requerimientos de ambas funciones de producción con respecto al capital. En esta estimación se define arbitrariamente la Unidad de Producción de Historia Económica (uphec) como una medida compuesta fundamentalmente de los inputs humanos de la actividad académica del profesor y cuya manifestación física y medible es una hora de actividad académica (clases, tutorías $\mathrm{y}$ otras actividades de ayuda al alumno) ejercitada por el profesor en la producción de Historia Económica. Un criterio más comprehensivo para comparar producción por persona incluiría también el trabajo escolástico, es decir, el número de artículos publicados en revistas profesionales con referees. Sin embargo, al no requerirse las publicaciones en el sistema español para las promociones o aumentos salariales, esto haría la comparación heterogénea e introduciría un sesgo en el ratio uphec/persona a favor de Estados Unidos $y$ en contra de España. En consecuencia, no se han tomado en cuenta las muchas y muy buenas aportaciones investigadoras de ambos grupos, sino solamente la actividad docente que ofrece una mejor homogeneidad para su medición.

El cut de un uphec sería, por lo tanto, la retribución laboral del historiador económico por cada hora trabajada y vendría definido como Cut $=\mathrm{W} /$ Uphec, es decir, costes salariales totales (W) divididos por el número de uphecs producido por cada historiador económico. Para una comparación significativa del cutusa con el cutesP (coste unitario del trabajo del uphec en Estados Unidos y en España, respectivamente) habrá que reducir ambos a una unidad monetaria común y usar el principio de paridad de poder adquisitivo a los tipos de cambio aplicados. Para los datos de nuestra estimación hemos usado las cifras de salarios para associate professors (el equivalente a profesores titulares) distribuidas por las asociaciones profesionales norteamericanas, es decir, 36.000 dólares brutos anuales para los historiadores económicos de departamentos de Economía y 30.000 para los de departamentos de Historia, y hemos supuesto una distribución al 50 por 100 de ambos. La cifra sería, por lo tanto, de 33.000 dólares brutos anuales en el caso americano y 26.354 para el caso español, es decir, 2.750 .000 pesetas una vez aplicado un tipo de 120 pesetas por dólar y un nivel general de precios 15 por 100 más bajo en España, como los observadores más cualificados - The Economist, por ejemplo- sugieren con frecuencia. El gráfico adjunto muestra los costes unitarios del trabajo para un uphec producido en América y en España. Para una comparación más exacta de ambas magnitudes, he supuesto el respeto escrupuloso por parte de los historiadores espa- 
ñoles de las catorce horas semanales de trabajo académico marcadas por la ley, y dos alternativas de veinte y cuarenta horas en el caso americano. En el caso mínimo de las veinte horas he supuesto una carga docente anormalmente baja de ocho horas lectivas semanales - un curso introductorio y otro avanzado- más nueve horas de despacho al alumno, más tres de servicios departamentales. Para las cuarenta horas semanales he supuesto la situación, más común, del horario completo académico de mañana a tarde con variaciones según los cámpuses. En cualquier caso, horarios semanales de mucho más de cuarenta horas son bastante frecuentes en el mundo académico norteamericano.

Como puede verse, el cut de un uphec en el caso español es 36,14 dólares, mientras que en las dos hipótesis para Estados Unidos son 31,70 y 15,85 , respectivamente. Es decir, que en el mejor de los casos nuestros oferentes acuden al mercado con una estructura de costes 14 por 100 más alta -128 por 100 en la hipótesis más probable - que la de sus colegas americanos. Para un cut similar al español, las horas semanales americanas habrían de descender al poco probable número de 17 . El cálculo exacto del número de horas más representativo para el caso americano es, como puede comprenderse, muy difícil, pero el alto cut del uphec español no deja lugar a dudas sobre nuestra desventaja.

\section{C.u.t. en dólares de un upbec según horas trabajadas por semana}

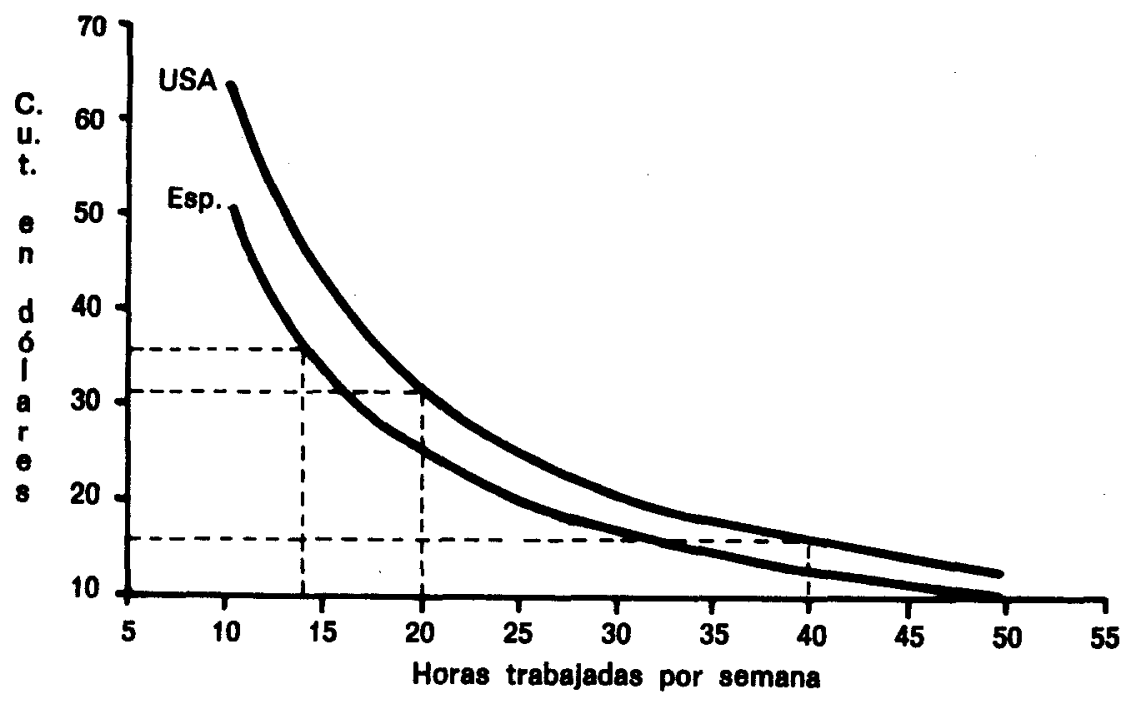


El gráfico y las cifras ponen de manifiesto el estado de indefensión de nuestra industria y las dificultades a las que nos tendríamos que enfrentar si en nuestro mercado se produjese un proceso de liberalización similar al americano. A pesar del carácter hipotético de este supuesto, es importante recordar que dentro de sólo cuatro años la unificación económica de Europa implicará una mayor integración de los mercados académicos, y que procesos como los descritos más arriba podrían darse en nuestra universidad si no se pone un remedio oportuno.

La solución no puede venir a través de fórmulas liberalizadoras de dudosa eficacia cuyo resultado ha conducido a la anteriormente expuesta situación de las ciencias sociales en las universidades americanas. Incluso defensores contumaces del libre cambio se han dado finalmente cuenta de que abandonar al mercado las decisiones económicas y académicas de la universidad puede llevar a una seria crisis de las humanidades. En este sentido, se están formando coaliciones de instituciones como la Carnegie Foundation for the Advancement of Teaching, el Co-operative Institutional Research Program y la American Association of State Colleges and Universities que han econcluido que el problema básico de la universidad es su falta de énfasis en las humanidades, entre ellas en la Historia Económica. En consecuencia, los expertos recomiendan acabar con el sistema de libre elección por parte del alumno e imponer una serie de asignaturas básicas de humanidades y ciencias sociales en los programas de todas las universidades. Este reconocimiento público del problema llevó al mismo Ronald Reagan a cambiar al final de su mandato su estrategia con respecto a la educación superior y a enfrentarse a las duras críticas de irresponsabilidad fiscal de sus correligionarios al aumentar los gastos federales en universidades durante el año fiscal 1989 hasta casi 19.000 millones de dólares en un momento en que el déficit presupuestario es el problema económico número uno del país.

En nuestro caso, el análisis económico lleva a una conclusión clara: la Historia Económica en nuestro país no podría competir en un mercado abierto y, por lo tanto, requiere la acción protectora del Estado. En concreto, debemos dirigir nuestros esfuerzos hacia los cinco siguientes fines: 1) que, dados su carácter de industria naciente y la necesidad de que el país sea autosuficiente en este área, la Historia Económica sea declarada industria de interés preferente. En este sentido, el Estado debería arbitrar un plan de subsidios e incentivos para aquellos departamentos de Historia Económica que, tras los estudios individuales oportunos, muestren un ratio cur/uphec más desfavorable; 2) que se mantenga el status presente de obligatoriedad de la asignatura, e incluso se amplíe a las áreas de enseñanza media y formación profesional; 3) que se establezca un arancel contra la importación de libros y material de Historia Económica que no hayan sido producidos en 
España, especialmente contra los procedentes de Estados Unidos e Inglaterra, y que al mismo tiempo se subsidie la exportación de obras españolas al exterior. Estas dos últimas medidas ampliarían el mercado, cuya insuficiencia actual es la causa primera de nuestra ineficiencia relativa; 4) que se posponga lo más posible la plena integración de España en el mercado académico europeo prevista para 1992 y que se prohíba, además, la entrada de profesores extranjeros a la universidad española y el acceso de estudiantes españoles a universidades extranjeras. Con respecto a esto, se podría conseguir un período de adaptación transitorio - aunque fácilmente renovable - de entre veinte y treinta años para que nuestra industria naciente consiga las economías de escala necesarias para competir en un mercado abierto; y, finalmente, 5) que el Estado ayude a la industria con un subsidio específico que adopte la forma de un sobresueldo a los historiadores económicos acompañado de una reducción de jornada laboral. Esta medida tendría un efecto declaratorio rotundo de la voluntad inequívoca del Estado en su apoyo a nuestra industria.

La administración de estas medidas debería centralizarse en un solo organismo encargado de la promoción y apoyo de la Historia Económica. En concreto, propongo la creación del INHE, Instituto Nacional de Historia Económica. El INHE sería financiado con cargo a los presupuestos generales del Estado y en sus estatutos se haría explícito el fin último de hacer a España autosuficiente en Historia Económica a la vez que independiente y libre de cualquier ingerencia exterior. El Instituto, al mismo tiempo, se propondría como metas el maximizar el empleo de los historiadores económicos españoles, garantizando un nivel mínimo de ingresos profesionales para todos.

Si algo sabemos los economistas de la historia de España es que los sectores $\mathrm{e}$ industrias que han progresado en nuestro país son aquellos que han sabido defender a tiempo sus intereses contra el mercado libre y la competencia exterior. Apliquemos, pues, nuestro conocimiento del pasado para prevenir y evitar una posible situación crítica en el futuro. 